\title{
Dithioacetal as a 1,1-zwitterion synthon. Synthesis of functionalized alkenes by the coupling of benzylic dithioacetals with another 1,1-zwitterion synthon
}

\author{
Hai-Yang Tu, ${ }^{\dagger}$ Yi-Hung Liu, Yu Wang and Tien-Yau Luh* \\ Department of Chemistry, National Taiwan University, Taipei 106, Taiwan, Province of China
}

Received 17 November 2004; revised 3 December 2004; accepted 6 December 2004

Available online 18 December 2004

Dedicated to Professor Iwao Ojima on the occasion of his 60th birthday

\begin{abstract}
Reaction of a dithioacetal sequentially with BuLi and alkyl bromide having an electron withdrawing substituent at the $\alpha$ position followed by treatment with neutral alumina gives the corresponding olefination product in moderate to good yields. (C) 2004 Elsevier Ltd. All rights reserved.
\end{abstract}

Direct coupling of a 1,1-zwitterion synthon with another kind of 1,1-zwitterion synthon appears to be an attractive route for the synthesis of carbon-carbon double bond. It is well documented that the dithioacetal functionality can serve as a dication synthon. ${ }^{1}$ In the presence of a catalytic amount of $\mathrm{NiCl}_{2}\left(\mathrm{PPh}_{3}\right)_{2}$, benzylic or allylic dithioacetals react with Grignard reagents to give the corresponding olefination products (Eq. 1). ${ }^{1}$ The reaction can also proceed with aliphatic substrates when trialkylphosphine ligands are employed. ${ }^{2}$ The major limitation of this olefination reaction is the use of Grignard reagents. Substrates containing functional groups such as carbonyl, cyano groups, terminal alkynes, etc., cannot be employed under the reaction conditions.

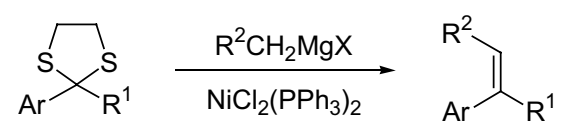

We have recently shown that propargylic dithioacetal 1 behaves like an allene-1,3-zwitterion equivalent. Treat-

\footnotetext{
Keywords: Dithioacetals; Olefination; Grignard active functional groups; Butyllithium; Dimerization.

* Corresponding author. Tel.: +886 22363 6288; fax: +88622364 4971; e-mail addresses: tyluh@ntu.edu.tw; tyluh@ccms.ntu.edu.tw

On leave from Department of Chemistry, China Central Normal University, Wuhan, Hubei Province.
}

ment of $\mathbf{1}$ with BuLi followed by alkyl halides gives regioselectively the corresponding alkylated alkynes $\mathbf{3}$ via an allenyl lithium or propargyllithium intermediate 2. ${ }^{3,4}$ The remaining carbon-sulfur bond in $\mathbf{3}$ can be replaced by a nucleophile (e.g., a Grignard reagent) in the presence of a nickel catalyst (Eq. 2) to give $4 .{ }^{3} \alpha$-Bromoacetate and related compounds are known to serve as 1,1-zwitterion equivalent in, for example, Darzens reaction to form epoxide with a carbonyl compound. ${ }^{5}$ It is envisaged that the thioether moiety in $\mathbf{3}$ may serve as a leaving group such that functionalized olefins can be obtained when such functionalized alkyl halides is used in the reaction shown in Eq. 2. As part of our continuing interests in the synthetic applications of propargylic dithioacetals, ${ }^{3,4}$ we report herewith the first examples of olefination of benzylic and propargylic dithiaocetals having a range of functional groups.

In the beginning of this study, a THF solution of benzophenone dithioacetal 5 was treated with 1.1 equiv of BuLi at $-78^{\circ} \mathrm{C}$ for $1 \mathrm{~h}$. To this mixture was added a THF solution of 1 equiv of phanacyl bromide at $-78^{\circ} \mathrm{C}$ and the mixture was gradually warmed to $\mathrm{rt}$ and stirred for an additional $10 \mathrm{~h}$. Neutral $\mathrm{Al}_{2} \mathrm{O}_{3}$ was added and the slurry was stirred for $0.5 \mathrm{~h}$ at $\mathrm{rt}^{6}{ }^{6}$ After filtration and usual workup, the corresponding olefination product 6 a was obtained in $75 \%$ yield. ${ }^{7}$ In a similar manner, the nitro-substituted olefin $\mathbf{6 b}$ was isolated in $54 \%$ yield. 


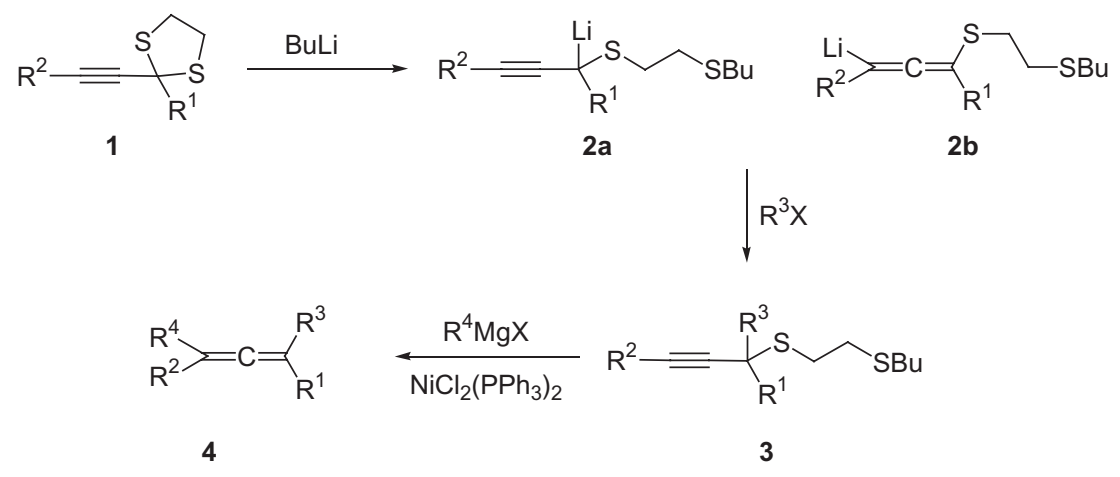<smiles>c1ccc(C2(c3ccccc3)SCCS2)cc1</smiles>

5

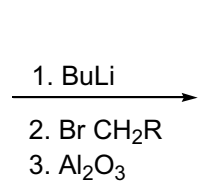

2. $\mathrm{Br} \mathrm{CH}_{2} \mathrm{R}$
3. $\mathrm{Al}_{2} \mathrm{O}_{3}$<smiles>[R]C=C(c1ccccc1)c1ccccc1</smiles>

6a $\mathrm{COPh} 75 \%$

6b $\mathrm{NO}_{2} \quad 54 \%$
The reactions with fluorenone derivative 7 behaved similarly. Thus, treatment of 7 with BuLi followed by phanacyl bromide or by $\alpha$-bromoacetonitrile afforded the corresponding olefination product $8 \mathbf{a}$ or $\mathbf{8 b}$ in $73 \%$ or $64 \%$ yield, respectively.<smiles>c1ccc2c(c1)-c1ccccc1C21SCCS1</smiles>

7

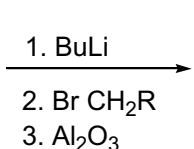

3. $\mathrm{Al}_{2} \mathrm{O}_{3}$

8a COPh $73 \%$
To our surprise, when $\alpha$-bromonitromethane was used as the electrophile, no olefination product was detected. Instead, the corresponding dimeric product 9 was isolated in $73 \%$ yield. The structure of 9 was unambiguously proved by spectroscopic methods and X-ray diffraction. ${ }^{8}$ It is well documented that fluorene derivative can readily undergo radical dimerization to form bifluorenyls ${ }^{9}$ and the nitroalkanes under strong basic conditions are known to facilitate electron transfer processes. ${ }^{10}$ Accordingly the fluorenyl anion thus generated may undergo rapid electron transfer to give the corresponding sulfur-substituted fluorenyl radical, which may dimerize leading to $\mathbf{9}$.

$$
7 \underset{\text { 1. BuLi }}{\stackrel{\text { 2. } \mathrm{BrCH}_{2} \mathrm{NO}_{2}}{\text { 3. } \mathrm{Al}_{2} \mathrm{O}_{3}}}
$$<smiles>CCCCCCC1(SC2(SCCCCC)c3ccccc3-c3ccccc32)c2ccccc2C2C=CC=CC21</smiles>

9

When propargylic dithioacetal $\mathbf{1 0}$ was allowed to react with $\mathrm{BuLi}$ followed by treatment with ethyl $\alpha$-bromoacetate, the corresponding enyne $\mathbf{1 1}$ was obtained in $71 \%$ yield. It is noteworthy that an ester group is stable under the reaction conditions. Accordingly, reaction of $\mathbf{1 2}$ under the same conditions afforded an $E$ and $Z$ (1:1) mixture of stereoisomeric 13 in $63 \%$ yield. Presumably, the replacement of the phenyl group in $\mathbf{1 0}$ by a butyl group in $\mathbf{1 2}$ may result in non-selective elimination giving a mixture of stereoisomers $\mathbf{1 3}$.

In summary, we have described the coupling of benzylic dithioacetals with methyl bromide having electron withdrawing substituent at the $\alpha$-position leading to the corresponding olefins in moderate yields. The reaction can be considered as a direct combination of two different zwitterion equivalents for the preparation of functionalized olefins. This reaction can thus compliment with our previous works on nickel-catalyzed olefination of the dithioacetals with Grignard reagents. ${ }^{1}$ As can be seen

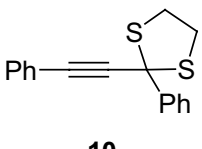

10

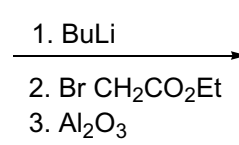

2. $\mathrm{Br} \mathrm{CH}_{2}$

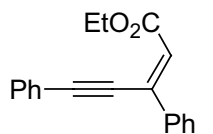

11

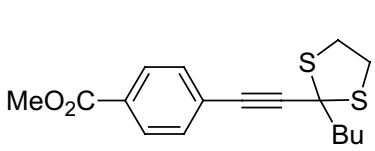

12

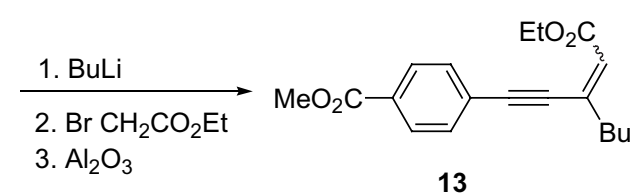

13 
from the examples, a range of Grignard active functional groups can be introduced under the reaction conditions. Further investigation on the use propargylic dithioacetals in organic synthesis is in progress in our laboratory.

\section{Acknowledgements}

This work is supported by the National Science Council and the Ministry of Education of the Republic of China.

\section{References and notes}

1. For reviews, see: (a) Luh, T.-Y. Acc. Chem. Res. 1991, 24, 257; (b) Luh, T.-Y. Synlett 1996, 201.

2. Huang, L.-F.; Huang, C.-H.; Stulgies, B.; de Meijere, A.; Luh, T.-Y. Org. Lett. 2003, 5, 4489.

3. (a) Tseng, H.-R.; Luh, T.-Y. J. Org. Chem. 1996, 61, 8685; (b) Tseng, H.-R.; Lee, C.-F.; Yang, L.-M.; Luh, T.-Y. J. Org. Chem. 1999, 64, 8582

4. (a) Lee, C.-F.; Yang, L.-M.; Hwu, T.-Y.; Feng, A.-H.; Tseng, J.-C.; Luh, T.-Y. J. Am. Chem. Soc. 2000, 122, 4992; (b) Zhang, L.-Z.; Chen, C.-W.; Lee, C.-F.; Wu, C.C.; Luh, T.-Y. Chem. Commun. 2002, 2336; (c) Lee, C.-F.; Liu, C.-Y.; Song, H.-C.; Luo, S.-J.; Tseng, J.-C.; Tso, H.H.; Luh, T.-Y. Chem. Commun. 2002, 2824; (d) Liu, C.-Y.; Luh, T.-Y. Org. Lett. 2002, 4, 4305.

5. For a review, see: Berti, G. Top. Stereochem. 1973, 7, 93.

6. Neutral alumina was employed to facilitate the elimination process. For example, in the absence of alumina, a significant amount of propargyl thioether precursor 3 (e.g., $\mathrm{R}^{1}, \mathrm{R}^{2}=\mathrm{Ph}, \mathrm{R}^{3}=\mathrm{CH}_{2} \mathrm{CO}_{2} \mathrm{Me}$ ) was obtained.
7. Typical procedure: To a THF solution $(60 \mathrm{~mL})$ of dithioacetal (1 mmol) was added under $\mathrm{N}_{2}$ atmosphere BuLi (1.1 equiv) at $-78^{\circ} \mathrm{C}$ and the mixture was stirred at $-78^{\circ} \mathrm{C}$ for $1 \mathrm{~h}$. A THF solution $(5 \mathrm{~mL})$ of alkyl bromide ( 1 equiv) was introduced. The mixture was gradually warmed to $\mathrm{rt}$ and stirred for an $10 \mathrm{~h}$. Neutral alumina $(15 \mathrm{~g})$ was then added and the slurry was stirred at $\mathrm{rt}$ for $0.5 \mathrm{~h}$. After filtration, the solvent was evaporated in vacuo and the residue was chromatographed on alumina to give the desired product.

8. Physical properties of 9: $\mathrm{mp} 100-103{ }^{\circ} \mathrm{C},{ }^{1} \mathrm{H}$ NMR $\left(400 \mathrm{mHz}, \mathrm{CDCl}_{3}\right) \delta 0.78(\mathrm{t}, J=7.0 \mathrm{~Hz}, 6 \mathrm{H}), 1.15-1.19$ $(\mathrm{m}, 8 \mathrm{H}), 1.80-1.90(\mathrm{~m}, 4 \mathrm{H}), 1.95(\mathrm{t}, J=7.0 \mathrm{~Hz}, 4 \mathrm{H}), 2.00$ $2.10(\mathrm{~m}, 4 \mathrm{H}), 7.05(\mathrm{t}, J=7.2 \mathrm{~Hz}, 4 \mathrm{H}), 7.17-7.26(\mathrm{~m}, 8 \mathrm{H})$, $7.31(\mathrm{~d}, J=7.6 \mathrm{~Hz}, 4 \mathrm{H}) ;{ }^{13} \mathrm{C} \mathrm{NMR} \delta 13.5,21.8,30.1,31.3$, $31.4,31.5,67.2,118.8,126.5,126.9,128.3,140.7,145.5$; HRMS calcd for $\mathrm{C}_{38} \mathrm{H}_{43} \mathrm{~S}_{4}$ : 627.2248, Found 627.2261; Xray data: triclinic $(P-1), a=9.3193(2), b=12.5142(2)$, $c=18.5513(4) \AA, \alpha=101.7280(11)^{\circ}, \beta=102.1700(11)^{\circ}$, $\gamma=108.0060(12)^{\circ}$, volume $=1718.04(6) \AA^{3}, \quad z=2$, and density $=1.212 \mathrm{~g} / \mathrm{cm}^{3}$.

9. (a) Bordwell, F. G.; Bausch, M. J.; Wilson, C. A. J. Am. Chem. Soc. 1987, 109, 5465; (b) Guthrie, R. D.; Wesley, D. P.; Perndygraft, G. W.; Young, A. T. J. Am. Chem. Soc. 1976, 98, 5870; (c) Guthrie, R. D.; Hartmann, C.; Neill, R.; Nutter, D. E. J. Org. Chem. 1987, 52, 736; (d) Bellos, K.; Stamm, H.; Speth, D. J. Org. Chem. 1991, 56, 6846; (e) Knjazhanski, S. Y.; Moreno, G.; Cadenas, G.; Belsky, V. K.; Bulychev, B. M. Tetrahedron 1999, 55, 1639.

10. (a) Al-Khalil, S. I.; Bowman, W. R.; Gaitonde, K.; Marley, M. A.; Richardson, G. D. J. Chem. Soc., Perkin Trans. 2 2001, 1557, and references therein; (b) Kornblum, N.; Michel, R. E.; Kerber, R. C. J. Am. Chem. Soc. 1966, 88, 5662; (c) Russell, G. A.; Danen, W. C. J. Am. Chem. Soc. 1966, 88,5663 . 